\title{
PRODUÇÕES DISCURSIVAS DE GÊNERO: UMA REFLEXÃO CRÍTICA SOBRE A LEI 12.318/2010 E A "SÍNDROME DA ALIENAÇÃO PARENTAL"
}

\author{
Glaucia Fernanda Oliveira Martins Batalha ${ }^{1}$ \\ Maiane Cibele de Mesquista Serra ${ }^{2}$
}

\section{RESUMO}

O artigo visa analisar a "Teoria Gardneriana da Síndrome da Alienação Parental" e a Lei 12.318/2010 numa perspectiva de gênero. Considera-se o discurso jurídico como "tecnologia" que produz o gênero e que naturaliza e difunde "regimes de verdade" sobre a diferença sexual ao se embasar nesta pseudo ciência para fundamentar a aprovação da Lei 12.318/2010 e a doutrina nacional, uma vez que instituem a representação da mulher (no âmbito da dissolução da união, seja por separação ou divórcio) como irracional, desequilibrada e alienadora. Para tanto, adota-se uma metodologia que contempla os seguintes procedimentos de pesquisa: pesquisa bibliográfica e pesquisa normativa.

Palavras-chave: Alienação Parental; Síndrome ; Lei; Discurso; Gênero.

\section{GENDER DISCURSIVE PRODUCTIONS: A CRITICAL REFLECTION ON LAW 12.318/2010 AND THE "PARENTAL ALIENATION SYNDROME"}

\begin{abstract}
This paper aims to analyze the "Gardnerian Theory of Parental Alienation Syndrome" and Law 12.318/2010 from a gender perspective. The legal discourse is considered as "technology" that produces gender and that naturalizes and diffuses "truth regimes" about sexual difference by being based on this pseudo science to support the approval of Law 12.318 / 2010 and national doctrine, once which institute the representation of women (within the framework of the dissolution of the union, either by separation or divorce) as irrational, unbalanced and alienating. To this end, a methodology is adopted that includes the following research procedures: bibliographic research and normative research.
\end{abstract}

Keywords: Parental Alienation; Syndrome; Law; Speech; Gender.

\section{Introdução}

\footnotetext{
${ }^{1}$ Mestre em Direitos Humanos pela Universidade de Federal do Pará- UFPA. Pós-graduada em Direito Administrativo e Administração Pública pela Universidade da Amazônia - UNAMA. Advogada pela OAB/MA. Professora e Coordenadora da Faculdade Santa Terezinha - CEST. Currículo Lattes: http://lattes.cnpq.br/1051668391621795. E-mail: glauciaf_martins@yahoo.com.br. ID ORCID: https://orcid.org/0000-0002-0458-0319.

${ }^{2}$ Mestre em Direito e Instituições de Justiça pela Universidade Federal do Maranhão - UFMA. Especialista em Docência na Educação Profissional e Tecnológica pelo SENAI CETIQT-RJ. Bacharel em Direito. Licenciada em Letras- Português e Inglês. Pós-graduada em Processo Civil. Advogada pela OAB/MA. Professora da Faculdade Santa Terezinha-CEST e Laboro. Currículo Lattes: http://lattes.cnpq.br/5010030376540550 . Email: maianeserra@hotmail.com. ID ORCID: http://orcid.org/0000-0002-0112-4465.
} 
O Direito de Família se constitui como ramo jurídico que orienta e regula relações familiares - sejam estas consaguíneas ou afetivas- e suas implicações no âmbito sociojurídico.

No Brasil, a formalização do Direito de Família ocorre a partir da edição do Código Civil de 1916, que por influência do direito canônico e romano, se funda sob a égide do modelo patriarcal e conservador de família.

O advento da Carta Magna de 1988 foi um marco nas configurações da família ao alterar o modelo anterior do Código Civil de 1916, "representante de uma sociedade fundiária, patriarcal, hierarquizada e fortemente marcada pelo cristianismo" (MADALENO, 2018, p.25).

A partir da Constituição Federal de 1988, o Direito de Família passa pelo fenômeno da constitucionalização, buscando, do ponto de vista material, consagrar "uma família plural e eudemonista fundanda, ainda, no principio da igualdade, que rompe com a hierarquização dos papeis e com o patriarcalismo". (RUZKY 2005, p. 163).

No entanto, em que pese o Direito de Família ter sido elevado ao status constitucional - e ter como princípios norteadores a dignidade da pessoa humana, a igualdade, solidariedade e eudemonismo - os vestígios do modelo sexista, patriarcal e da subalternirzação social e histórica das mulheres permanecem.

É nesse contexto que o presente artigo almeja desenvolver uma reflexão crítica em torno da Lei 12.318/2010 acerca do que ferrenhamente se tem denominado de "Síndrome da Alienação Parental”.

Desse modo, a Lei 12.318/2010, promulgada em 26 de agosto de 2010, surge com o objetivo de disciplinar a "Alienação Parental” e prevê mecanismos de combate a essa prática.

Todavia, a justificação do Projeto de Lei 4.053/2008 proposto pelo Deputado Federal Regis de Oliveira- que posteriormente transformou-se na Lei Ordinária 12.318/2010- se ergue com base na teoria do psiquiatra norte-americano do Richard Gardner, que carece de sistematização e de testes de conhecimentos compilados por meio de estudos e pequisas científicas.

Além disso, a lei e grande parte da doutrina nacional desconsideram as críticas e as polêmicas quanto à “Teoria de Gardner" nos Estados Unidos da America e em outros países. Vejamos:

A partir da Lei n. 12.318, de agosto de 2010, tendo aqui recebido aplausos quase unânimes, o que parece ocorrer de forma burlescamente acrítica, até porque nenhum 
outro país editou lei acerca do tema e os Tribunais e sociedade de psiquiatria dos mais tradicionais países ocidentais a rechaçam consistentemente.

É a partir de tal problemática que intenta-se buscar vestígios sobre uma possível configuração no saber jurídico, fazendo circular enunciados que instauram certezas e definem comportamentos que tornam-se vetores de violência de gênero na construção social.

É o que pontua Ribeiro (2019, p.33):

Tendo em vista que o discurso pode ser tanto pronunciado quanto escrito, Michel Foucault (2013) supõe que em diversas sociedades a produção do discurso passa por processos de seleção e organização de procedimentos que tendem a reforçar o poder de quem os detêm e/ou dominam, tornando-os cada vez mais legítimos. Nessa perspectiva, o discurso ao invés de ser homogêneo e natural, é previamente pensado e estabelecido por dispositivos e instituições (em relações de poder) que têm a pretensão de alcançar "verdades". Com isso, a maneira como as instituições sociais produzem os discursos é pelo menos parcialmente, violenta.

Desta feita, com base em Foucault, leva-se em consideração o fato de que os saberes juridicos edificam, validam e disseminam proposições e estratégias discursivas que exluem e naturalizam diferenças nas relações de gênero e reforçam hierarquias, desigualdades, discriminações e totalitarismos relativos ao gênero na estrutura social.

A reprodução do discurso fortalece e propaga, determinada lei, regra ou norma. Vejamos (FOUCAULT, 2012, p. 10):

Por mais que o discurso seja aparentemente bem pouca coisa, as interdições que o atingem revelam logo, rapidamente, sua ligação com o desejo e com o poder. Nisto não há nada de espantoso, visto que o discurso - como a psicanálise nos mostrou não é simplesmente aquilo que manifesta (ou oculta) o desejo; é, também, aquilo que é o objeto do desejo; e visto que - isto a história não cessa de nos ensinar - o discurso não é simplesmente aquilo que traduz as lutas ou os sistemas de dominação, mas aquilo porque, pelo que se luta, o poder do qual nos queremos apoderar.

Nesta perspectiva, a estrutura social é encarregada por presenvar tais valores e cultivar estratégias para legitimar e difundir o discurso, transformando este em expressão social e verdade oficialmente aceita. "Nós os conhecemos em nosso sistema de cultura: são os textos religiosos ou jurídicos, são também esses textos curiosos, quando se considera o seu estatuto, e que chamamos de literários "e; em certa medida textos científicos" (FOUCAULT, 2012, p. 21).

Desse modo, leva-se em consideração que a lei (e sua justificação) e a doutrina jurídica acerca da "Síndrome da Alienação Parental" produzem e reproduzem "verdades" sobre aquilo que apresentam, manifestando-se como forte instrumento de poder, pois 
controlam e restrigem.

Por sua vez, seus enunciados, previamente elaborados, são validados por constituíremse como produtos de uma formação especializada, qual seja: a do/a jurista.

Assim, neste artigo busca-se compreender as produções discursivas da lei (e sua justificação) e da doutrina jurídica em torno da "Síndrome da Alienação Parental".

Visa-se problematizar as representações de gênero ${ }^{3}$ constituídas nessas produções discursivas, desejando compreender, assim, algumas questões: Quais enunciados a lei e a doutrina jurídica utilizam para registrar a "Síndrome de Alienação Parental"? Como esses enunciados são apresentados? Como o discurso jurídico- como tecnologias de gênero ${ }^{4}$ constroem e marcam sujeitos/as dentro de contextos e interesses específicos.

A pesquisa teve como substrato e referencial teórico autores da perspectiva pósestruturalista como Judith Buttler e Michel Foucault.

Para concretização dos fins propostos, adota-se uma metodologia que contempla os seguintes procedimentos de pesquisa: pesquisa bibliográfica e pesquisa normativa.

No tocante às fontes pesquisadas, examinaram-se livros e artigos afetos à temática da "Síndrome da Alienação Parental”, legislações específicas como a o Projeto de Lei 4.053/2008 e a Lei 12. 318/2010 (Lei da Alienação Parental).

O presente artigo constitui-se numa sequência de cinco seções. A primeira discorre sobre noções introdutórias a respeito da temática. Já a segunda trata acerca da gênese da "Teoria” do Psiquiatra Richard Gardner.

Por sua vez, a terceira apresenta e reflete questões importantes em torno do nascimento da Lei 12. 318/2010.

No quarto momento, constrói-se a alegação de que o discurso jurídico trata-se de uma "tecnologia" que produz o gênero ao apresentar marcações da diferença numa perspectiva binária, configurando modelos de feminilidades e masculinidades, de modo que a linearidade de tais narrativas acabam por implantar e reproduzir "regimes de verdade" que instituem a representação da mulher como irracional, desequilibrada e alienadora no momento

\footnotetext{
${ }^{3} \mathrm{O}$ recorte da pesquisa restringe-se a relações familiares heterossexuais, afastando, por exemplos, as modalidades de famílias decorrentes de uniões homossexuais, transexuais, etc.

4 Com base em Teresa de Laurentis, "tecnologia de gênero" se constitui em técnicas que constroem os sujeitos como "mulheres" e "homens" de acordo com o sistema sexo/gênero que funciona com base em distinções culturais que posicionam o feminino e o masculino como posições complementares e excludente .
} 
de uma separação ou divórcio ${ }^{5}$.

A quinta traz considerações finais - não com o objetivo de esgotar assunto tão densona tentativa de promover o debate e o pensamento crítico no seio jurídico e acadêmico em torno do tema.

Tecidos aspectos introdutórios, remete-se para a gênese do conceito e a contextualização crítica da "Síndrome da Alienação Parental".

\title{
2. A Gênese: Richard Gardner e a "Teoria Gardneria da Síndrome da Alienação Parental"
}

Em 1985, Richard Alan Gardner, o psiquiatra norte-americano do Departamento de Psquiatria Infantil da Faculdade de Medicina da Universidade de Columbia, foi o responsável pela construção da "Teoria da Síndrome da Alienação Parental".

Segundo os estudos produzidos por Gardner, o termo "Síndrome da Alienação Parental" foi criado para se referir a um distúrbio psicológico evidente em crianças expostas e envolvidas em disputa de guarda, sendo a principal característica de tal transtorno a alienação - de forma exacerbada e injustificada - de um dos genitores, mas geralmente o pai.

Vejamos (GARDNER, 1991, n.p, tradução livre). ${ }^{6}$ :

\begin{abstract}
Originalmente, achei que estava observando manifestações de simples "lavagem cerebral". No entanto, logo percebi que as coisas não eram tão simples e que muitos outros fatores estavam funcionando. Nesse sentido, apresentei o termo síndrome de alienação parental. Eu uso o termo para me referir a um distúrbio no qual uma criança é obcecada por depreciar e denigrir um dos pais (mais frequentemente do pai) que é injustificada ou exagerada.?
\end{abstract}

Extrai-se, ainda, da "Teoria de Gardner" que a "Síndrome da Alienação Parental"

\footnotetext{
${ }^{5}$ A expressões "separação" e "divórcio" são usadas neste estudo de forma indiferenciada. Na verdade, o que se objetiva é relacionar os termos à ruptura e dissolução de uma união.

${ }^{6}$ Originally, I thought I was observing manifestations of simple "brainwashing." However, I soon came to appreciate that things were nor so simple and that many other factors were operative. Accordingly, I introduced the term parental alienation syndrome.

I use the term to refer to a disturbance in which a child is obsessed with deprecation and criticism of a parent (more often the father) denigration that is unjustified or exaggerated. Tradução livre.

${ }^{7}$ Originally, I thought I was observing manifestations of simple "brainwashing." However, I soon came to appreciate that things were nor so simple and that many other factors were operative. Accordingly, I introduced the term parental alienation syndrome.

I use the term to refer to a disturbance in which a child is obsessed with deprecation and criticism of a parent (more often the father) denigration that is unjustified or exaggerated. Tradução livre.
} 
representaria uma "lavagem cerebral" perpetrada de forma sistemática e consciente por um dos genitores (via de regra, a mãe), no sentido de programar a criança a difamar o outro genitor (geralmente o pai) com o intuito de destruição do vínculo afetivo. Nos casos mais graves, esta campanha compreenderia até mesmo acusações falsas de abuso sexual de crianças (GARDNER, 1991).

Pontua Siqueira (2018, p. 43), que Gardner posiciona de maneira reducionista e sexista a mulher como a alienadora :

Afirmava, ainda, de forma simplista e com claro preconceito ao gênero feminino
que $90 \%$ dos alienadores eram mães "furiosas" que encontram nas falsas
alegações de abuso sexual, poderosas armas contra seus ex-maridos a fim de
obterem a guarda, cortar a visitação ao pai ou vingar-se.
Além disto, Gardner, maliciosamente sugeria que quando uma mulher acusa o
pai de molestar o filho, ela poderia estar projetando suas próprias inclinações
sexuais por ele. (grifos nossos)

Com efeito, Gardner na maioria dos artigos de sua autoria sobre a temática, ao tratar acerca do genitor alienador - aquele que visa a desconstituição do vínculo familiar do filho com o outro familiar- estabelece a mulher como a maior praticante dessa conduta. Ou seja, para o psiquiatra, a mãe, por excelência, instala a "Síndrome da Alienação Parental" nos próprios filhos.

Diante das críticas sobre ser a "Síndrome da Alienação Parental" uma prática de discriminção de gênero, alega Gardner no texto "Parental Alienation Syndrome vs. Parental Alienation: Which Diagnosis Should Evaluators Use in Child-Custody Disputes?” (2002, n.p, tradução livre) :

\begin{abstract}
Nos últimos anos, tornou-se "politicamente arriscado" e até "politicamente incorreto" descrever as diferenças de gênero. Tais diferenciações são aceitáveis para transtornos como câncer de mama e doenças do útero e dos ovários. Mas uma vez que se passe para o reino dos padrões de personalidade e distúrbios psiquiátricos, é provável que alguém seja rapidamente rotulado de "sexista" (independente do sexo). E isso é especialmente o caso se for um homem que está afirmando que um distúrbio psiquiátrico específico é mais provável de ser prevalente em mulheres. ${ }^{8}$
\end{abstract}

Não obstante suas justificativas, Gardrner na secção intitulada "Síndrome da Alienação Parental e Acusações de Abuso Sexual" persiste em enunciar a mulher como alienadora:

\footnotetext{
${ }^{8}$ In recent years it has become "politically risky" and even "politically incorrect" to describe gender differences. Such differentiations are acceptable for such disorders as breast cancer and diseases of the uterus and ovaries. But once one moves into the realm of personality patterns and psychiatric disturbances, one is likely to be quickly branded a "sexist" (regardless of one's sex). And this is especially the case if it is a man who is claiming that a specific psychiatric disorder is more likely to be prevalent in women. Tradução livre.
} 
Uma falsa acusação de abuso sexual às vezes surge como um derivado do PAS. Tal acusação pode servir como uma arma extremamente eficaz em uma disputa de custódia de crianças. $\mathrm{Na}$ verdade, é provavelmente uma das mais poderosas manobras de vingança já utilizadas por uma mulher cujo marido a abandonou. Claro, há pais que promulgarão uma acusação de abuso sexual por outras razões. Uma mulher pode querer se afastar do marido permanentemente e há muito planejou a separação. A acusação de abuso sexual pode servir para acelerar significativamente o processo e pode resultar em sua remoção permanente ${ }^{9}$.

A despeito de suas "constatações", escritas a partir de experiências clínicas, sem sistematizações e embasamentos científicos - e, portanto, superficiais - evidencia-se que Gardner constrói "evidências", através de uma pedagogia médica e jurídica, de que as mulheres no contexto de uma separação e/ou divórcio tornam-se irracionais, histéricas e manipuladoras.

Acerca de tal entendimento corrobora Sottomayor (2011, p. 83-84)

As teorias de GARDNER têm uma origem sexista e pedófila, na medida em que o seu autor, em trabalho publicado em 1992, intitulado "True and false accusa- tions of child sex abuse" 40 , entendia que as mulheres eram meros objectos, receptáculos do sémen do homem, e que as parafilias, incluindo a pedofilia estão ao serviço de exercitar a máquina sexual para a procriação da espécie humana $\mathrm{Na}$ verdade, a SAP revelou ser uma interpretação misógina da recusa da criança em conviver com o progenitor não guardião, que presume a maldade, o egoísmo e a irracionalidade das mulheres, gerando situações de risco para as crianças e provocando um retrocesso nos direitos humanos das mulheres e das crianças

E acrescenta o fato de Gardner considerar algo natural e aceitável:

RICHARD GARDNER, nas primeiras edições dos seus trabalhos, mostrava ser tolerante com a pedofilia e com o abuso sexual de crianças, tendo feito afirmações públicas no mesmo sentido, divulgadas pelo Independent: «A pedofilia, acrescentou GARDNER, "é uma prática generalizada e aceita entre literalmente bilióes de pessoas". Interrogado, novamente, por um entrevista- dor sobre o que devia fazer uma mãe, se a sua filha se queixasse de abuso sexual por parte do pai, Gardner respondeu: "O que deve ela dizer? Não digas isso sobre o teu pai. Se o disseres, eu bato-te”.

Do exposto, pode-se se afirmar que as "constatações científicas" de Gardner se constroem mediante a lógica patriarcal, donde o homem é visto como o chefe de família, o detentor da propriedade das mulheres e crianças. Ideologia esta que subaterniza e assujeita mulheres e crianças considerando-as objetos a serem invisibilizados.

\footnotetext{
${ }^{9}$ A false sex-abuse accusation sometimes emerges as a derivative of the PAS. Such an accusation may serve as an extremely effective weapon in a child-custody dispute. In fact, it is probably one of the most powerful vengeance maneuvers ever utilized by a woman whose husband has left her. Of course, there are parents who will promulgate a sex-abuse accusation for other reasons. A woman might want to remove herself from her husband permanently and has long planned the separation. The sex-abuse accusation can serve to speed up the process significantly and may result in his permanent removal. Tradução livre.
} 
Neste conxteto, pode-se afirmar que a "Teoria Gardneriana da Síndrome da Alienação Parental" fomenta o discurso sexista, pedófilo e demarca lugares sociais do gênero, contribuindo para a manutenção das relações de poder e da dominação do masculino sob o feminino, bem como representa mais uma forma de violência contra a mulher.

\title{
3. Da "Teoria Garderiana" à Lei $12.318 / 2010$ no Brasil
}

Como sinalizado anteriormente, em face da ausência de credibilidade científica a “Teoria Garderiana da Síndrome da Alienação Parental” é rejeitada em muitos países.

Ao contrário da unanimidade de que desfruta a "Síndrome da Alienação Parental" no meio jurídico brasileiro, a "Teoria de Gardner" é alvo de severas críticas em países de tradição científica como Inglaterra, País de Gales, Canadá, Portugal, Argentina, Espanha, dentre outros, que rechaçam o uso da pseudociência.

A OMS - Organização Mundial da Saúde - OMS, a Associação Americana de Psiquiatria -APA e a Associação Espanhola de Neuropsiquiatria -AEN não reconhecem a "Síndrome da Alienação Parental" como um quadro psicopatológico por não possuir base empírica. (FERREIRA; ENZWEILER, 2019)

Distintamente dos demais países, no Brasil, após célere tramitação no Legislativo, a Lei 12.318/2010 foi sancionada em agosto de 2010, prevendo sanções ao genitor que causar impedimentos à convivência do(s) filho(s) com o outro responsável.

Ferreira e Enzeweiler (2019, p. 158) atentam que:

\begin{abstract}
as locuções "alienação parental" (AP) e "síndrome da alienação parental" (SAP) passaram, há pouco, a fazer parte do vocabulário jurídico nacional, sendo utilizadas pelos Tribunais de todo o país só muito recentemente, em casos envolvendo divórcios conturbados. (...) a partir da edição da Lei n. 12.318, de agosto de 2010, tendo aqui recebido aplausos quase unânimes, o que parece ocorrer de forma burlescamente acrítica, até porque nenhum outro país editou lei acerca do tema e os Tribunais e sociedades de psiquiatria dos mais tradicionais países ocidentais a rechaçam consistentemente. (grifo nosso)
\end{abstract}

Salienta-se que a exposição de motivos do Projeto de Lei 4.053//2008 (que serve de base para o nascimento da Lei 12. 318/2010), bem como o posicionamento dos psicólogos forenses e juristas brasileiros, são fundamentados majoritariamente nos estudos de Richard Gardner e carecem de reflexões críticas quanto ao combate da "Teoria" de Gardner nos EUA e demais países. É o que pontua Sousa e Brito (2011, p. 270): 
A despeito das polêmicas e controvérsias que envolvem o assunto (Escudero, Aguilar, \& Cruz, 2008), a proposta de Gardner difundiu-se rapidamente no Brasil e em outros países, levando alguns a pensar que a suposta síndrome havia se tornado uma epidemia em todo o mundo (Álvarez, n.d). No Brasil, como evidenciado em pesquisa empreendida por Sousa (2010) sobre o tema, a escassez de debates e estudos acerca do conceito de SAP, bem como a ausência de questionamentos sobre a ideia de um distúrbio infantil ligado às situações de disputa entre pais separados, vêm contribuindo para a naturalização do assunto de forma acrítica. Tal cenário colabora, ainda, com a visão de que muitos casos de litígio conjugal têm como consequência o surgimento da denominada síndrome.

Do exposto, percebe-se que no Brasil, a aprovação da Lei da Alienação Parental se deu sem a apreciação de pesquisas e de estudos aprofundados em torno do tema, naturalizando um suposto quadro psicopatológico infantil, sem base científica comprovada.

Nesse sentido, ressalta-se que o Projeto de Lei no 4.053/2008 traz em seu bojo como justificativa a "Teoria Gardneriana". Tese esta, como já ratificado, que possui uma imensa fragilidade científica e que oferece soluções fáceis, simples e lineares para resolução de problemas complexos como o processo de ruptura da conjugalidade.

A justificação do Projeto de Lei, além de não fazer a distinção e confundir os termos “Alienação Parental" e "Síndrome da Alienação Parental", é elaborado com base no artigo "Síndrome de Alienação Parental e a Tirania do Guardião - Aspectos Psicológicos, Sociais e Jurídicos" que constrói a figura do alienador como um tirano (para não dizer, alienadoras tiranas), bem como no texto de Maria Berenice Dias intitualdo "Síndrome de Alienação Parental: o que é isso?".

É o que se evidencia na justificação do Projeto de Lei 4.053/2008, do Deputado Regis Oliveira, que tem como base o artigo da jurista Maria Berenice Dias (2010, n.p):

No entanto, muitas vezes a ruptura da vida conjugal gera na mãe sentimento de
abandono, de rejeição, de traição, surgindo uma tendência vingativa muito
grande. Quando não consegue elaborar adequadamente o luto da separação,
desencadeia um processo de destruição, de desmoralização, de descrédito do ex-
cônjuge. Ao ver o interesse do pai em preservar a convivência com o filho, quer
vingar-se, afastando este do genitor.
Para isso cria uma série de situações visando a dificultar ao máximo ou a impedir a
visitação. A este processo o psiquiatra americano Richard Gardner nominou de
"síndrome de alienação parental": programar uma criança para que odeie o genitor
sem qualquer justificativa. Trata-se de verdadeira campanha para desmoralizar o
genitor. O filho é utilizado como instrumento da agressividade direcionada ao
parceiro. A mãe monitora o tempo do filho com o outro genitor e também os
seus sentimentos para com ele en $^{10}$. (grifo nosso)

No que diz respeito à confunsão na definição dos termos "Alienação Parental" e 
"Síndrome da Alienação Parental", trata-se de uma realidade recorrente não apenas na justificação do de Lei 4.053/2008, como também nas publicação nacionais em torno da temática.

Indiscriminadamente a doutrina jurídica se vale, muitas das vezes, dos termos como sinônimos, o que de certa forma contribui para apresentar a "Teoria Gardneriana" como verdade única e definitiva ${ }^{11}$.

É o que sinaliza Sousa em seu estudo em torno do que considera (in) definições acerca da "Síndrome da Alienação Parental" (2014, 1. 2456), pois nas publicações nacionais nota-se de forma contumaz confusão quanto à definição da "Síndrome da Alienção Parental", ao ponto de esta aparecer referida à figura do genitor e não à criança.

Num cenário de dissolução de uma união, permeado muitas das vezes por sentimentos contraditórios e de litigiosidade, confundir que todo o afastamento, justificado ou não, entre a prole e o genitor decorre da implantação da "Síndrome" descrita por Gardner é temerário, uma vez que corre-se o risco de se naturalizar comportamentos e conflitos relacionais como "Síndrome da Alienação Parental".

Somado a isto, a Lei da Alienação Parental foi aprovada por um Parlamento eminentemente masculino $^{12}$ (FERREIRA; ENZWEILER, 2019, p.158):

\begin{abstract}
A nova lei, diz silenciosa minoria, por ter sido aprovada por um Parlamento marcadamente masculino (...) em que boa parte de seus mebros se vê ali espelhada e "na pele" do devedor de alimentos aos filhos e å ex-mulher -, exprime forte preconceito de gênero, mostra-se antinômica e se encontra replete de conceitos vagos e sanções (a serem aplicadas logicamente, na imensa maioria dos casos às mulheres) no mínimo temerárias, por terem estas como destinatários finais, perversamente, não a ex-mulher, mas justamente os filhos que todos dizem querer preserver.
\end{abstract}

Frisa-se, também, que a Lei 12. 318/2010 aplica a "Terapia da Ameaça", que culmina com a transferência da guarda para o progenitor "alienado". Portanto, seguindo em literalidade a "Teoria Gardneriana", qual seja: a alteração de guarda do filho, proibição de contato com o genitor alienante, obrigação de convivio com o genitor alienado mesmo contra a vontade da criança ou adolescente (com a finalidade de a "reprogramar").

É o que dispõe o artigo $6^{\circ}$ da Lei 12. 318/2010 (BRASIL. 2010):

Art. $6^{\circ}$ Caracterizados atos típicos de alienação parental ou qualquer conduta que dificulte a convivência de criança ou adolescente com genitor, em ação autônoma ou

\footnotetext{
${ }^{12}$ Apenas 10, 5\% do Congresso Nacional é feminino do conjunto de deputados federais.
} 
incidental, o juiz poderá, cumulativamente ou não, sem prejuízo da decorrente responsabilidade civil ou criminal e da ampla utilização de instrumentos processuais aptos a inibir ou atenuar seus efeitos, segundo a gravidade do caso:

I - declarar a ocorrência de alienação parental e advertir o alienador;

II - ampliar o regime de convivência familiar em favor do genitor alienado;

III - estipular multa ao alienador;

IV - determinar acompanhamento psicológico e/ou biopsicossocial;

V - determinar a alteração da guarda para guarda compartilhada ou sua inversão;

VI - determinar a fixação cautelar do domicílio da criança ou adolescente;

VII - declarar a suspensão da autoridade parental.

Assim, verifica-se que a Lei 12.318/2010 é um campo fértil para a perpetuação da violência e do tratamento desigual com base no gênero, uma vez que institucionliza e sustenta a supremacia masculina, gerando, assim, uma desigualdade manifesta e opressora sobre as mulheres.

\section{Para além da Lei da Alienação Parental: notas sobre a produção discursiva de gênero no Direito de Família}

Neste ponto, objetiva-se realizar a análise do discurso jurídico como tecnologia ${ }^{13}$ que produz o gênero e que naturaliza e propaga "regimes de verdade" sobre as marcações da diferença de gênero. Para tanto baseia-se no aporte teórico de Judith Butler e Michel Foucault.

No livro "Problemas de gênero", numa perspectiva analítica pós-estruturalista , Judith Butler (2017) questiona a linearidade entre sexo, gênero, desejo e práticas sexuais através de uma constituição performativa do gênero inteligível- que legitima a diferença sexual.

Para Butlher a linearidade de tais narrativas - baseadas numa lógica binária configuram e referendam modelos de mulheres e de homens, que podem ser analisadas sob a perspectiva da performatividade de gênero.

A teórica rebate em seu texto o postulado de distinção entre sexo e gênero, onde o primeiro corresponderia ao domínio biológico e o segundo ao domínio sociocultural, afirmando que tanto o sexo quanto o gênero são construídos socialmente, sendo inconcebível o sexo como algo natural.

\footnotetext{
${ }^{13}$ Utilize-se a definição de "tecnologia de gênero", todavia, com ressalvas, já que este é baseado na indicação do sistema sexo/gênero, rejeitado por Judith Butler que considera tanto o sexo quanto o gênero são construídos socialmente, sendo inconcebíevel o primeiro como natural.
} 
Se o caráter imutável do sexo é contestável, talvez o próprio construto chamado 'sexo' seja tão culturalmente construído quanto o gênero; a rigor, talvez o sexo sempre tenha sido o gênero, de tal forma que a distinção entre sexo e gênero revelase absolutamente nenhuma. Se o sexo é, ele próprio, uma categoria tomada em seu gênero, não faz sentido definir o gênero como a interpretação cultural do sexo (BUTLER, 2017, p. 25).

E vai além. Para a Butler a distinção entre sexo e gênero também é uma construção social, política, histórica e discursiva que assegura de forma eficaz as diferenças e/ou desigualdades assentadas numa lógica da natureza. Ou seja, para a autora o sexo - enquanto categoria biológica- é pré-discursivo:

O gênero não está para a cultura como o sexo para a natureza, ele também é o meio discursivo/cultural pelo qual a "natureza sexuada" ou o "sexo natural" é produzido e estabelecido como "pré-discursivo", anterior à cultura, uma superfície politicamente sobre a qual age a cultura. [...] Na conjuntura atual, já está claro que colocar a dualidade do sexo num domínio pré-discursivo é uma das maneiras pelas quais a estabilidade interna e a estrutura binária do sexo são eficazmente asseguradas. (BUTLER 2017, p.25)

Segundo Ribeiro as discussões levantadas por Judith Butler em "Problemas de Gênero" dão sustentáculo para se repensar categorias postas como naturais (RIBEIRO, 2019, p. 24):

Butler chama atenção para o fato de que "ser mulher" não denota uma identidade comum, assim como não se trata de uma categoria estável ou permanente. Desse modo, a autora ressalta que não é possível pensar as questões de gênero sem refletir as relações de poder em que esta categoria é discursivamente constituída.

Nessa lógica, a diferença entre mulheres e homens é tida como algo natural, sendo (re) produzida como uma verdade absoluta e inconteste, além de ser sustentada e pautada por discursos médicos, religiosos, midiáticos, pedagógicos, e, como se sugere neste artigo, nos discursos jurídicos.

Desta feita, pode-se asseverar que as políticas identitárias tendem a universalizar o termo "mulher" e construir sua definicão dentro de um sistema binário de significações que precisa ser repensado.

Para fins de construção deste trabalho, ao se relacionar gênero e direito, é mister compreender que o discurso jurídico- mais precisamente do ramo do Direito de Família - deve ser visto como uma série de enunciados que produzem o gênero nas mais diversas formas.

Por meio do conteúdos produzidos na lei (aqui, especificamente, no Projeto de Lei 4.053/2008 e na Lei 12. 318/210) e na doutrina jurídica as representações sobre o gênero são 
produzidas, reproduzidas e atualizadas constantemente.

No artigo "Tecnologias de gênero e as lógicas de aprisionamento", os autores pontuam que para Lauretis,

é preciso separar gênero da diferença sexual e passer a conceber o gênero como produto de várias tecnologias (efeito da linguagem, do imaginário, do desenvolvimento complexo de várias tecnologias políticas produzidas nos corpos). Para ela, os gêneros são então produzidos por uma tecnologia, uma maquinaria de produção (que formam discursos que se apoiam nas instituições do Estado - como a família, a escola etc.), criando as categorias homem e mulher para todas as pessoas. O gênero é produto de várias tecnologias sociais, uma maquinaria de produção que vem de discursos e práticas discursivas das autoridades religiosas, legais ou científicas, da medicina, da mídia, da família, da religião, da pedagogia, da cultura popular, dos sistemas educacionais, da psicologia, da arte, da literatura, da economia, da demografia etc., que se apoiam nas instituições do Estado. (PINAFI, 2011, p. 270)

Assim, resta evidente que o discurso e as práticas discursivas jurídicas tratam-se de uma tecnologia/ uma maquinária que produz o gênero, demarcando as categorias homem e mullher, instrumentalizando a diferença de gênero que se apoia nas instituições do Estado, tais como a família, a lei e o Poder Judiciário.

A partir deste referencial teórico edifica-se o argumento de que o discurso jurídico ao se embasar na "Teoria Gardneriana" para justificar a aprovação da Lei 12.318/2010, bem como fundamentar a doutrina no âmbito do Direito de Família nacional- narram e produzem as marcações da diferença de gênero, que configuram modelos de feminilidades e masculinidades e que institucionalizam a representação da mulher como irracional, insana, desequilibrada e alienadora.

Nesta diapasão, pode-se relacionar a representação desta mulher irracional insana, desequilibrada e alienadora com a segregação do louco que Focault (1970, p.10 -11) discorre em "A ordem do discurso":

Existe em nossa sociedade outro princípio de exclusão: não mais a interdição, mas uma separação e uma rejeição. Penso na oposição razão e loucura. (...) o louco é aquele cujo discurso não pode circular como o dos outros: pode ser que sua palavra seja considerada nula e que não seja acolhida, não tendo verdade nem importância, não podendo testemunhar na justiça (..)

Neste panorama, a loucura aparece como a antítese da razão. Assim como no discurso médico e jurídico utilizado para fundar Lei 12.318/2010, donde a razão é declarada domínio masculino e a histeria/loucura é propriedade feminina.

Destarte, já que a razão trata-se de um dominínio masculino, as mulheres estão dela excluídas, devendo, portanto, suas palavras serem silenciadas, anuladas e invisibilisadas. 
De modo que é " assim que a loucura presente na definição do ser mulher faz dela alvo, presa, vítima, objeto de controle, de dominação e, sobretudo, de um desejo irrefreável, justificativa de todas as exclusões e violências" (SWAIN, 2017, 1. 1048).

À vista disso, cria-se no imaginário social uma imagem do feminino e das mulheres cuja a essência é dotada "naturalmente" de desequilibrio, de perturbarção, de histerização e, também, de alienação, sendo a loucura difundida para legitimar exclusões e violências e para negar às mulheres um lugar de fala e visibilidade, como evidencia-se na órbita da Teoria de Gardneriana.

\section{Considerações Finais}

A partir da análise do estudo que embasou este artigo, observa-se que no cenário jurídico nacional a Teoria de Gardner se propagou rapidamente. Todavia, o que chama atenção é a escassez que reflexões críticas em torno da "Síndrome da Alienação Parental".

Frisa-se que tal movimento é diamentralmente oposto a de muitos países europeus que rebatem ferrenhamente a existência da pseudosíndrome, o que acaba por fomentar e circular enunciados que instauram certezas e evidências de "uma verdade inquestionável" nos ares tupiniquis.

Enfatiza-se ao longo do trabalho que a "Síndrome da Alienação Parental" - criada por Richard Gardner - não possui respaldo científico e reconhecimento pelos manuais classificatórios de psiquiatria, o que por si só já se revela ser uma temeridade.

Ademais, a generalização da temática "Síndrome da Alienação Parental”, legitimada através do discurso jurídico reproduz e naturaliza tecnologias de gênero - estabelecendo modelos de feminilidades e masculinidades - que atribuem diferenças incontornáveis, em hierarquia e assimetria, entre homens e mulheres e torna-se um campo fértil para a perpetuar a violência, a desigualdade e a opressão da mulher.

Nesse sentido:

(...) A construção política do sujeito procede vinculada a certos objetivos de legitimação e de exclusão, e essas operações políticas são efetivamente ocultas e 
naturalizadas por uma análise política que toma as estruturas jurídicas como seu fundamento. O poder jurídico "produz" inevitavelmente o que alega meramente representar; consequentemente, a política tem de se preocupar com essa função dual do poder: jurídica e produtiva. Com efeito, a lei produz e depois oculta a noção de "sujeito perante a lei", de modo a invocar essa formação discursiva como premissa básica natural que legitima, subsequentemente, a própria hegemonia reguladora da lei (BUTLER, 2017, p. 20).

Portanto, pode-se afirmar que tais marcações de diferenças entre homens e mulheres se trasmutam em desigualdades através dos processos históricos e culturais que universalizam os estereótipos de masculinidade e feminilidade e validam exclusões e invisibilidades de gênero.

É com base nesse panorama que se realiza no presente artigo uma reflexão crítica em torno da Lei 12.318/2010 e da "Teoria da Síndrome da Alienação Parental”, uma vez que o fundamento destas se ergue no pilar sexista de que as mães são as maiores alienadoras no momento da dissolução de uma união conjugal.

Frise-se que embora a Lei 12. 318/2010 não mencione o termo "Síndrome da Alienação Parental", a confusão de definições entre esta e a "Alienação Parental” é prejudicial, já que a "Teoria da Síndrome” se ergue nessa concepção sexista.

E, nesse contexto, essa concepção está por trás do nascimento da legislação, que além de ajudar a banalizar o termo "Síndrome" como uma verdade incontestável, difunde e institucionaliza a figura da mãe como alienadora, ao partir da presunção e da absolutização de que a mulher age com tal conduta por estar ressentida de ter sido "rejeitada".

É o que argumenta Castilho (2019, n.p) em matéria da Revista Crescer intitulada "Lei da Alienação Parental desviou-se do propósito de proteger as crianças, submetendo-as aos abusadores":

Em pesquisa jurisprudencial, que estou coordenando, já encontramos, inclusive, a confusão no uso das expressões SAP e AP (Alienação Parental). É uma concepção fundamentalmente contrária às mulheres. Embora a lei seja aplicável a homens e mulheres, na prática, também se percebe uma aplicação maior em desfavor das mulheres.

O fato é que diante do rompimento da união conjugal, constantemente, surgem conflitos e questões de cunho emocionais mal resolvidas.

Por vezes, evidenciam-se envolvimentos de sentimentos como o amor, o ódio, a mágoa, a raiva, a pena, etc, haja vista que, embora tenha havido uma separação fática e, até jurídica, pode não ter havido a separação emocional. 
Em meio a esse cenário possivelmente há pais fragilizados. Assim como os filhos podem estar -de forma voluntária ou involuntária - envolvidos no cerne dessa ruptura.

A descontrução e dissolução dos vínculos familiares trata-se de uma problemática densa. Todavia, a Teoria de Gardner e a Lei 12. 318/2010, através de um viés de cunho androcêntrico, além d propagar desigualdade e violência de gênero, naturaliza comportamentos e conflitos relacionais como indícios de "Síndrome".

Ou seja, seguindo o pensamento de Foucault entende-se que o discurso jurídico enseja e estimula a construção do objeto da "Síndrome da Alienação Parental", qual seja: encaixa os conflitos relacionais e o estabelecimento de alianças entre a genitora e o (s) filho(s) com a existência do pseudo distúrbio psicopatológico do infante.

Observa-se, portanto, que os discursos médicos e jurídicos (objeto deste trabalho) generalizantes sobre a "Síndrome da Alienação Parental" - além de ocasionarem alarde social- acabam por estabelecê-la como uma epidemia no seio da ruptura conjugal. Trazendo, desta feita, para a dissolução e para o litígio conjugal uma solução restritiva e simplória de um assunto multifatorial e de densa complexidade.

Aliado a isso, tais discursos se constituem através da imagem da mulher como alienadora, irracional e histérica, à semelhança da figura do louco evidenciada na lógica foulcautiana. Concepção esta essencialmente contrária às mulheres, que estimula desigualdades e invisibilidades dentro da Lei 12. 318/2010 e dentro do processo judicial.

Com isso, o seio social, os profissionais envolvidos (em especial, juristas), se convencem acerca da necessidade de intervenção estatal na família em litígio, por meio de medidas coercitivas e punitivas previstas na Lei 12. 318/2010.

Ressalta-se, que o posicionamento do presente artigo, não nega que a ruptura e o litígio conjugal são situações que podem envolver questões de saúde mental. O que combatese é a inadequação da "Teoria Gardneriana" e, por conseguinte, a "Síndrome da Alienação Parental", bem como o fundamento que valida da Lei 12. 318/2019, uma vez que estas se estruturam com base na discriminção de gênero, que legitimam exclusões, violências e que negam às mulheres um lugar de fala e visibilidade.

Diante do exposto, considera-se razoável o Projeto de Lei do Senado (PLS 498/2018) que objetiva a revogação da Lei 12.318/2019.

Entende-se que a Lei 12. 318/2019 se desvia do propósito de proteger a criança ou adolescente e de apaziguar e mediar a relações familiares ao utilizar de forma sumária a 
"Terapia da Ameaça", sem tentar compreender os motivos da rejeição do infante e sem averiguar quais os comportamentos do progenitor rejeitado que originaram a recusa da criança ou adolescente.

Por fim, compreende-se que a Lei 12.318/2019 viola o Princípio Constitucional da Igualdade (art. 5o, Constituição Federal de 1988) ao validar em sua justificativa a desigualdade entre homens e mulheres e coopera para a conservação das relações de poder e da dominação do masculino sob o feminino.

\section{Referências}

BRASIL, [Constituição (1988)]. Constituição da República Federativa do Brasil. Brasília, DF: Presidência da República, [2016]. Disponível em: http://www.planalto.gov.br/ccivil_03/constituicao/constituicao.htm . Acesso: 1 jun. 2019.

Lei $n^{\circ} 12.318$, de 26 de agosto de 2010. Dispõe sobre a Alienação Parental e altera o art. 236 da Lei no 8.069, de 13 de julho de 1990. Brasília, DF: Câmara dos Deputados, [2010]. Disponível em: http://www.planalto.gov.br/ccivil_03/constituicao/constituicao.htm . Acesso: 1 jun. 2019.

Projeto de Lei n $^{\circ} 4053$ de 2008. Dispõe sobre a alienação parental.

Brasília, DF: Câmara dos Deputados, [2008]. Disponível em:

https://www.camara.leg.br/proposicoesWeb/fichadetramitacao?idProposicao=411011. Acesso em: 01 jun. 2019.

. Projeto de Lei no 498/2018. Revoga a Lei da Alienação Parental. Brasília,

DF: Senado Federa, [2018]. Acesso em: 30 ago. 2019

BUTLER, Judith. Problemas de gênero: feminismo e subversão da identidade. Trad: Renato Aguiar. 13a edição. Rio de Janeiro: Civilização Brasileira, 2017.

Vida Precária. Contemporânea- Revista de Sociologia da UFSCar. São

Carlos, Departamento e Programa de Pós-Graduação em Sociologia da UFSCar, 2011, n. 1, p. 13- 33.

DIAS, Maria Berenice. Síndrome da alienação parental, o que é isso?. Disponível em: http://www.mariaberenice.com.br/manager/arq/(cod2_504)1_sindrome_da_alienacao_pare ntal_o_que_e isso.pdf . Acesso em: 1 jun. 2019. 
DINI, Aline. Lei da Alienação Parental desviou-se do propósito de proteger as crianças, submetendo-as aos abusadores. Revista Crescer. Disponível em: https://revistacrescer.globo.com/Voce-precisa-saber/noticia/2019/07/lei-da-alienacaoparental-desviou-se-do-proposito-de-proteger-criancas-submetendo-aos-abusadores-dizespecialista.html. Acesso em: 19 ago. 2019.

FERREIRA, Cláudia Galiberne; ENZWEILER, Romano José. A invisibilidade de crianças e mulehres vítimas da perversidade da Lei de Alienação Parental: Pedofilia, Violência e Barbarismo. Florianópolis: Conceito Editorial, 2019.

FOUCAULT, Michel. A ordem do discurso: aula inaugural no College de France, pronunciada em 2 de dezembro de 1970. Trad: Laura Fraga de Almeida Sampaio. 23a ed. São Paulo: Edições Loyola, 2012.

GARDNER, R. A. Legal and Psychotherapeutic Approaches to the Three Types of Parental Alienation Syndrome Families: When Psychiatry and the Law Join Forces. Court Review, volume 28, Number 1, Spring 1991, p. 14-21, Americam Judges Association. Disponível em: https://www.fact.on.ca/Info/pas/gardnr01.htm . Acesso em: 30 mai. 2019.

Parental alienation syndrome vs. parental alienation: Which diagnosis should evaluators use in child-custody disputes? American Journal of Family Therapy, 30(2), 93-115, (2002). Disponível em: https://www.fact.on.ca/Info/pas/gard02b.htm. Acesso: 1 jun. 2019.

LAURETIS, Teresa de. A tecnologia do gênero. Tradução: Suzana Funck. In: HOLLANDA, Heloisa Buarque de (Org.). Tendências e impasses: o feminismo como crítica da cultura. Rio de Janeiro: Rocco, 1994, 206-241.

MADALENO, Ana Caroline (et al). Síndrome de Alienação Parental: importância da detecção- aspectos legais e processuais . 5 edicao rev. atual. e ampl. Rio de Janeiro: editora Forense, 2018.

SIQUEIRA, Tanise de. Alienação Parental: a ponta do "iceberg" para institucionalização da pedofilia. Revista Empodere. n.04. p. 42-47. Brasil: Revista Empodere, 2018.

SOUSA, Sandra Maria Nascimento (et al.) Fazendo e Desfazendo Gênero 2. São Luís: EDUFMA, 2019.

PAINS, Clarissa. Brasil tem menos parlamentares mulheres do que 151 países. Rio de Janeiro: O Globo, 2018. Disponível em: https://oglobo.globo.com/sociedade/brasil-temmenos-parlamentares-mulheres-do-que-151-paises-22462336 . Acesso em: 15 jul. 2019.

PITANGA, Carolina Vasconcelos. Produções discursivas em campanhas publicitárias: gênero e interseccionalidades. 2017. 193 f. Tese (Doutorado)- Curso de Ciências Sociais, Universidade Federal do Maranhão, São Luís, 2017.

PINAFI, Tânia (et al). Tecnologias de gênero e as lógicas de aprisionamento. Revista Bagoas. n. 06. p. 267-282. Rio de Janeiro: Bagoas, 2011. Disponivel em: 
http://www.cchla.ufrn.br/bagoas/v05n06art11_pinafietal.pdf. Acesso: 15 ago.2019.

RIBEIRO, Geysa Fernandes. Em briga de marido e mulher não se mete a colher?: um estudo s sobre violência de gênero em jornais do Maranhão (2015-2017).2019. Dissertação (Mestrado) - Curso de Ciências Sociais, Universidade Federal do Maranhão, São Luís, 2019.

RUZYK, Carlos Eduardo Pianovski, Famílias Simultâneas: da Unidade Codificada à Pluralidade Constitucional. Rio de Janeiro: Renovar, 2005.

SOTTOMAYOR, Maria Clara. Uma análise crítica da síndrome de alienação parental e os riscos da sua utilização nos tribunais de família. Julgar.n. 13. Portugal: Coimbra Editora, 2011. Disponível em: http://julgar.pt/wp-content/uploads/2015/10/073-107-Alienaçãoparental.pdf . Acesso em: 19 ago. 2019

. A fraude da síndrome de alienação parental e a protecção das crianças vítimas de abuso sexual. Texto correspondente à comunicação proferida na Conferência Internacional "O Superior Interesse da Criança e o Mito da "Síndrome de Alienação Parental", no painel "A síndrome de alienação parental e os riscos para os direitos das mulheres e das crianças", 3 de Novembro de 2011. Disponível em: http://www.eas.pt/wpcontent/uploads/2014/01/A-fraude-da-SAP-e-a-protecç_o-das-crianças-v\%C3\%ADtimas-deabuso-sexual.pdf . Acesso em: 19 ago. 2019.

SOUSA, Analicia Martins de. Síndrome da Alienação Parental: um novo tema nos juízos de família. São Paulo: Cortez, 2014.

WAQUIM, Bruna Barbieri. Alienação Parental Induzida: aprofundado o estudo da Alienação Parental. Rio de Janeiro: Lumen Juris, 2018. 